\title{
NIR Absorbing AzaBODIPY Dyes for pH Sensing
}

\author{
Gugu Kubheka ${ }^{1}$, John Mack ${ }^{1, * \mathbb{D}}$, Tebello Nyokong ${ }^{1 \mathbb{D}}$ and Zhen Shen ${ }^{2, *}$ \\ 1 Institute for Nanotechnology Innovation, Department of Chemistry, Rhodes University, \\ Grahamstown 6140, South Africa; gugu_kubheka@yahoo.com (G.K.); t.nyokong@ru.ac.za (T.N.) \\ 2 State Key Laboratory of Coordination Chemistry, School of Chemistry and Chemical Engineering, \\ Nanjing University, Nanjing 210046, China \\ * Correspondence: j.mack@ru.ac.za (J.M.); zshen@nju.edu.cn (Z.S.); \\ Tel.: +27-46-603-7234 (J.M.); +86-25-8968-6679 (Z.S.)
}

Academic Editor: M. Salomé Rodríguez-Morgade

Received: 23 July 2020; Accepted: 12 August 2020; Published: 13 August 2020

check for updates

\begin{abstract}
Two near-infrared (NIR) absorbing di(thien-2-nyl)-di(dimethylanilino)azaBODIPY dyes 2a and $\mathbf{2} \mathbf{b}$ were synthesized and characterized that differ depending on whether the dimethylaniline substituents are introduced at the 3,5- or 1,7-positions of the azaBODIPY core. The main spectral bands lie at 824 and $790 \mathrm{~nm}$, respectively, in $\mathrm{CH}_{2} \mathrm{Cl}_{2}$. The effect of substituent position on the photophysical and $\mathrm{pH}$ sensing properties was analyzed through a comparison of the optical properties with the results of time-dependent density functional theory (TD-DFT) calculations. Protonation of the dimethylamino nitrogen atoms eliminates the intramolecular charge transfer properties of these compounds, and this results in a marked blue-shift of the main absorption bands to 696 and $730 \mathrm{~nm}$, respectively, in $\mathrm{CH}_{2} \mathrm{Cl}_{2}$, and a fluorescence "turn-on" effect in the NIR region. The $\mathrm{pH}$ dependence studies reveal that the $\mathrm{pK}_{\mathrm{a}}$ values of the non-protonated $\mathbf{2 a}$ and $\mathbf{2} \mathbf{b}$ molecules are ca. $6.9( \pm 0.05)$ and $7.3( \pm 0.05)$, respectively, while that of the monoprotonated species for both dyes is ca. $1.4( \pm 0.05)$ making them potentially suitable for use as colorimetric $\mathrm{pH}$ indicators under highly acidic conditions.
\end{abstract}

Keywords: aza-BODIPY dye; $\mathrm{pH}$ sensing; intramolecular charge transfer; photophysical properties; $\mathrm{pK}_{\mathrm{a}}$ values

\section{Introduction}

Near-infrared (NIR) region absorbing dyes are essential for various applications in fields as diverse as materials science and medicine [1]. NIR dyes are advantageous in a biomedical context due to reduced background absorption, fluorescence, and light scattering, resulting in improved sensitivity [2]. Boron azadipyrromethene (azaBODIPY) dyes are of particular interest, since the incorporation of an aza-nitrogen atom into the boron dipyrromethene (BODIPY) chromophore is one of the main strategies used to red shift the main spectral band into the NIR region [3]. Among the various possible NIR chromophores, there has been an increasing focus on azaBODIPY dyes in recent years due to their favorable photophysical properties, such as high photostability, and their structural versatility and ease of modification at all positions on the azaBODIPY core [4,5]. Different strategies have been used to develop dyes with highly red-shifted spectral bands, such as attaching electron-donating and withdrawing group at the 3,5- and 1,7-positions, respectively; replacing the phenyl groups with smaller five-membered heterocyclic rings [5-8]; and the addition of fused rings to the pyrrole rings of the azaBODIDY core [9]. When electron-donating aryl groups, such as dimethylaniline, are introduced at the 3,5-positions there is a large red-shift of the main spectral band, since there is a marked decrease in the HOMO-LUMO gap [10]. The red-shifts that are observed when a five-membered ring system is incorporated into the structure have been ascribed to increased delocalization that arises from enhanced co-planarity with the azaBODIPY core and reduced torsion angles relative to structures that 
contain phenyl rings [5]. Substitution with thiophene rings also provides scope for more effectively conjugated donor-acceptor compounds [11].

The inclusion of dimethylaniline substituents into the structures of azaBODIPY dyes can generate pronounced photophysical changes as a result of substrate recognition [12,13], due to changes in the intramolecular charge transfer (ICT) properties of the dyes. Therefore, this ICT switching mechanism can potentially be used to form $\mathrm{pH}$ indicators [12] or in the detection of small metal ions such as $\mathrm{Ca}^{2+}, \mathrm{Cu}^{2+}$, and $\mathrm{Mg}^{2+}$ when a more elaborate amine receptor is used [14]. ICT systems are advantageous for sensor applications, since the use of highly fluorescent dyes results in inner-filter effects, due to the bias introduced by the $\mathrm{pH}$-dependent emission [14]. A limited number of $\mathrm{pH}$-sensitive amino moiety functionalized azaBODIPY dyes have been previously reported as indicator dyes, and different spectroscopic methods, such as absorption and fluorescence, have been used to measure the $\mathrm{pH}$ of the probes $[1,12,14]$. For example, McDonnell et al. reported the sensing properties of 1,7-diphenyl-3,5-di-(dimethylanilino)azaBODIPY (1), which is structurally similar to the dyes reported herein [12].

In this study, we report the synthesis of dimethylaniline and thien-2-yl substituted aza-BODIPY dyes $\mathbf{2} \mathbf{a}$ and $\mathbf{2} \mathbf{b}$ as NIR and $\mathrm{pH}$-responsive chromophores by varying the position of the substituents between 1,7- and 3,5-positions (Figure 1). The aim of the study is to investigate the effect of the substituent and position on the photophysical properties and $\mathrm{pK}_{\mathrm{a}}$ values, and to form azaBODIPY dyes with spectral bands red shifted beyond $750 \mathrm{~nm}$. To the best of our knowledge, there have been very few reports on non-protonated azaBODIPY dyes that exhibit no fluorescence emission and hence provide scope for use as "turn-on" fluorescence $\mathrm{pH}$ sensing indicators in the NIR region. The goal was to use the ICT properties associated with the dimethylaniline groups to achieve this.
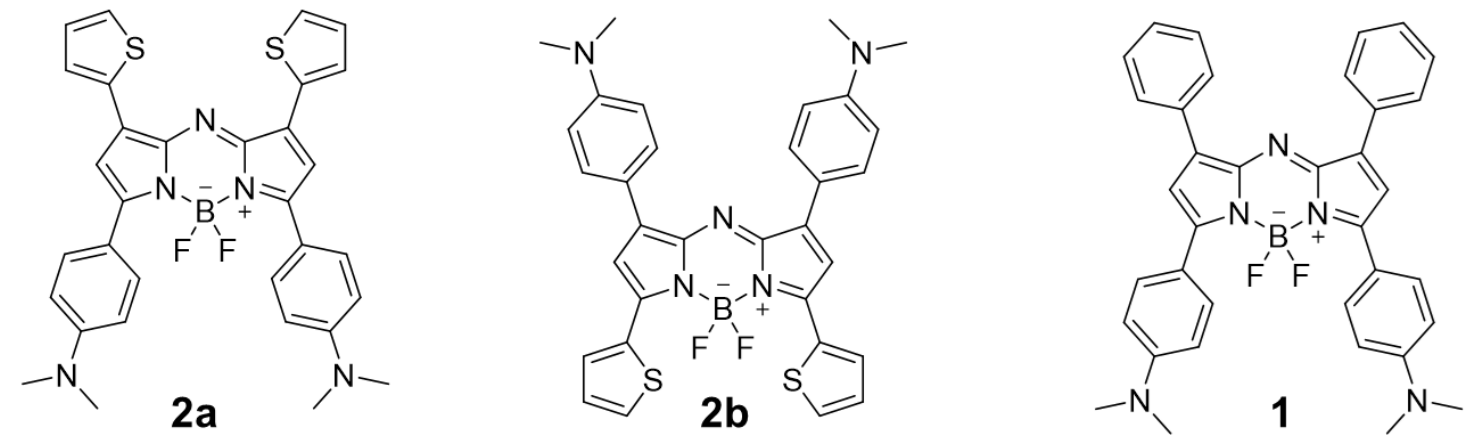

Figure 1. A comparison of the molecular structures of $\mathbf{2 a}$ and $\mathbf{2} \mathbf{b}$ with that of $\mathbf{1}$, which was reported previously by McDonnell et al. [12].

\section{Results}

\subsection{Synthesis}

AzaBODIPYs $\mathbf{2 a}$ and $\mathbf{2} \mathbf{b}$ were synthesized according to literature procedures (Scheme 1) $[5,15,16]$. After initially forming chalcone 3 from the appropriate aryl aldehyde and acetophenone and subsequently converting it to nitro-derivative 4, azadipyrromethene 5 was obtained by heating 4 under reflux with ammonium acetate $\left(\mathrm{NH}_{4} \mathrm{OAc}\right)$ in $n$-butanol $(n-\mathrm{BuOH})$ for $24 \mathrm{~h}$. After separation on column chromatography, the $\mathrm{BF}_{2}$ moiety was introduced to 5 using boron trifluoroetherate $\left(\mathrm{BF}_{3} \cdot \mathrm{OEt}_{2}\right)$ and diisopropylethylamine (DIPEA) in $\mathrm{CH}_{2} \mathrm{Cl}_{2}$ under reflux for $6 \mathrm{~h}$. The products were isolated as bluish-purple and blue for $\mathbf{2 a}$ and $\mathbf{2 b}$, respectively, in moderately high yields. The target compounds were characterized by ${ }^{1} \mathrm{H}$ NMR and FTIR spectroscopy and mass spectrometry. The ${ }^{1} \mathrm{H}$ NMR spectrum of 2a (Figures S1 and S2, Supporting Information) contains peaks at 7.24 (double doublet), 7.69 (double doublet) and 8.06 (double doublet) ppm that can be assigned on the basis of integration to the thien-2-yl groups, while the corresponding peaks for $2 \mathbf{b}$ lie at 7.23 (double doublet), 7.54 (doublet) and 8.32 (doublet) ppm (1-, 2- and 3-H in Figures S1 and S2, Supporting Information). Singlets at 
7.37 and $6.99 \mathrm{ppm}$, respectively, can be attributed to the 2,6-positions of the aza-BODIPY core (4-H in Figures S1 and S2, Supporting Information). Two doublets at 6.86 and $8.22 \mathrm{ppm}$ were detected in the spectrum of $2 \mathrm{a}$ with coupling constants of $9.6 \mathrm{~Hz}$ indicating the presence of two adjacent protons (5and 6-H in Figure S1, Supporting Information) that can be assigned to the dimethylaniline moiety, while the corresponding peaks for $\mathbf{2} \mathbf{b}$ peaks lie at 6.77 and $8.07 \mathrm{ppm}$ (5- and 6-H in Figure S2, Supporting Information). The methyl protons (7- and 8-H in Figures S1 and S2, Supporting Information) lie at $3.15 \mathrm{ppm}$ for $\mathbf{2} \mathbf{a}$ and $3.09 \mathrm{ppm}$ for $\mathbf{2} \mathbf{b}$. The chemical shifts for $\mathbf{2} \mathbf{a}$ lie upfield of those observed for $\mathbf{2} \mathbf{b}$. This provides an indication of more efficient ICT from the donor to the acceptor group. Molecular ion peaks are observed at $m / z=594.96$ for $\mathbf{2 a}$ and 595.00 for $\mathbf{2 b}$ (Figures S3 and S4, Supporting Information) in the MS data in close agreement with the calculated value of $\mathrm{m} / z=595.19$.<smiles>[R]C=CC([R])=O</smiles>

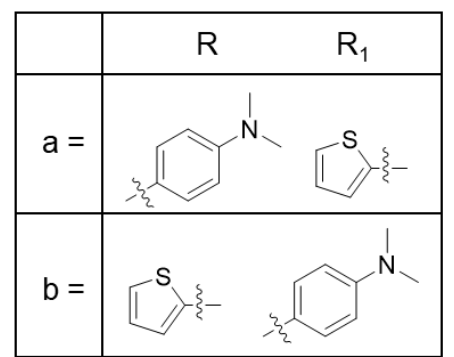

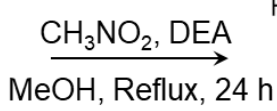
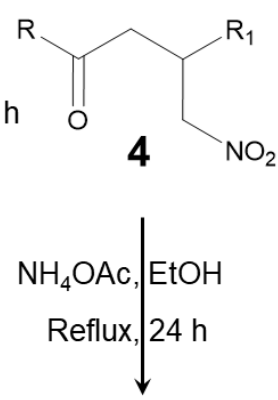

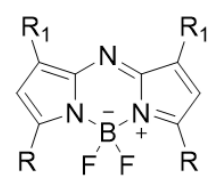

2

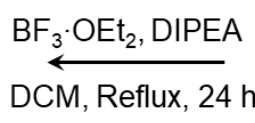

DCM, Reflux, $24 \mathrm{~h}$

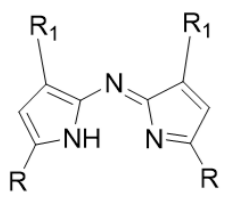

5

Scheme 1. Synthesis of azaBODIPYs $\mathbf{2 a}$ and $\mathbf{2 b}$.

\subsection{Photophysical Properties}

The photophysical properties of $\mathbf{2} \mathbf{a}$ and $\mathbf{2} \mathbf{b}$ were investigated by UV-visible absorption and fluorescence emission spectroscopy in solvents of differing polarity. The absorption spectra of $2 \mathbf{a}$ and $\mathbf{2} \mathbf{b}$ consist of two prominent bands that lie in the 570-600 and 810-860 nm regions for $\mathbf{2 a}$ and $660-690$ and 770-850 $\mathrm{nm}$ regions for $\mathbf{2} \mathbf{b}$ (Figure 2). In comparison to the spectrum of $\mathbf{1}$ in toluene [12], the absorption band maximum of the main spectral band for $\mathbf{2 a}$ is red shifted by $18 \mathrm{~nm}$ (Table 1 ).

Table 1. Wavelengths of the main spectral bands of $\mathbf{2} \mathbf{a}$ and $\mathbf{2} \mathbf{b}$ in a range of different solvents.

\begin{tabular}{ccccccc}
\hline & DMSO & $\mathbf{C H}_{\mathbf{2}} \mathbf{C l}_{\mathbf{2}}$ & THF & Toluene & Benzene & Ref. \\
\hline $\mathbf{1}$ & $-{ }^{1}$ & - & - & 798 & - & {$[12]$} \\
$\mathbf{2 a}$ & 859 & 824 & 819 & 816 & 814 & - \\
$\mathbf{2 b}$ & 810 & 790 & 786 & 776 & 779 & - \\
\hline \multicolumn{7}{c}{ 1 No value available. }
\end{tabular}

Both $\mathbf{2 a}$ and $\mathbf{2 b}$ exhibit marked solvatochromism (Figure 2 and Table 1). The solvatochromism is stronger for $\mathbf{2} \mathbf{b}$ where the dimethylaniline groups are substituted at the 1,7-positions, since the ICT character of the $S_{1}$ state is expected to be particularly strong due to the effect of the electron-donating effect of these substituents on the HOMO which is expected to have large MO coefficients at the 3,5-positions [17]. Both dyes exhibit linear Beer-Lambert plots in all solvents studied, which points to an absence of aggregation. In contrast with $\mathbf{1}$ [12], when the fluorescence properties of $\mathbf{2} \mathbf{a}$ and $\mathbf{2} \mathbf{b}$ were studied in polar, polar aprotic and non-polar solvents, no emission was observed. The fluorescence quenching is related to ICT character in the $S_{1}$ state that is associated with the presence of the 
electron-donating thien-2-yl and dimethylanilino groups and an electron-deficient azaBODIPY core [18]. The heavy atom effect of the thiophene sulfur atoms is the most likely explanation for differences in the fluorescence properties of $\mathbf{2} \mathbf{a}$ and $\mathbf{2} \mathbf{b}$ relative to those of $\mathbf{1}$ [12].
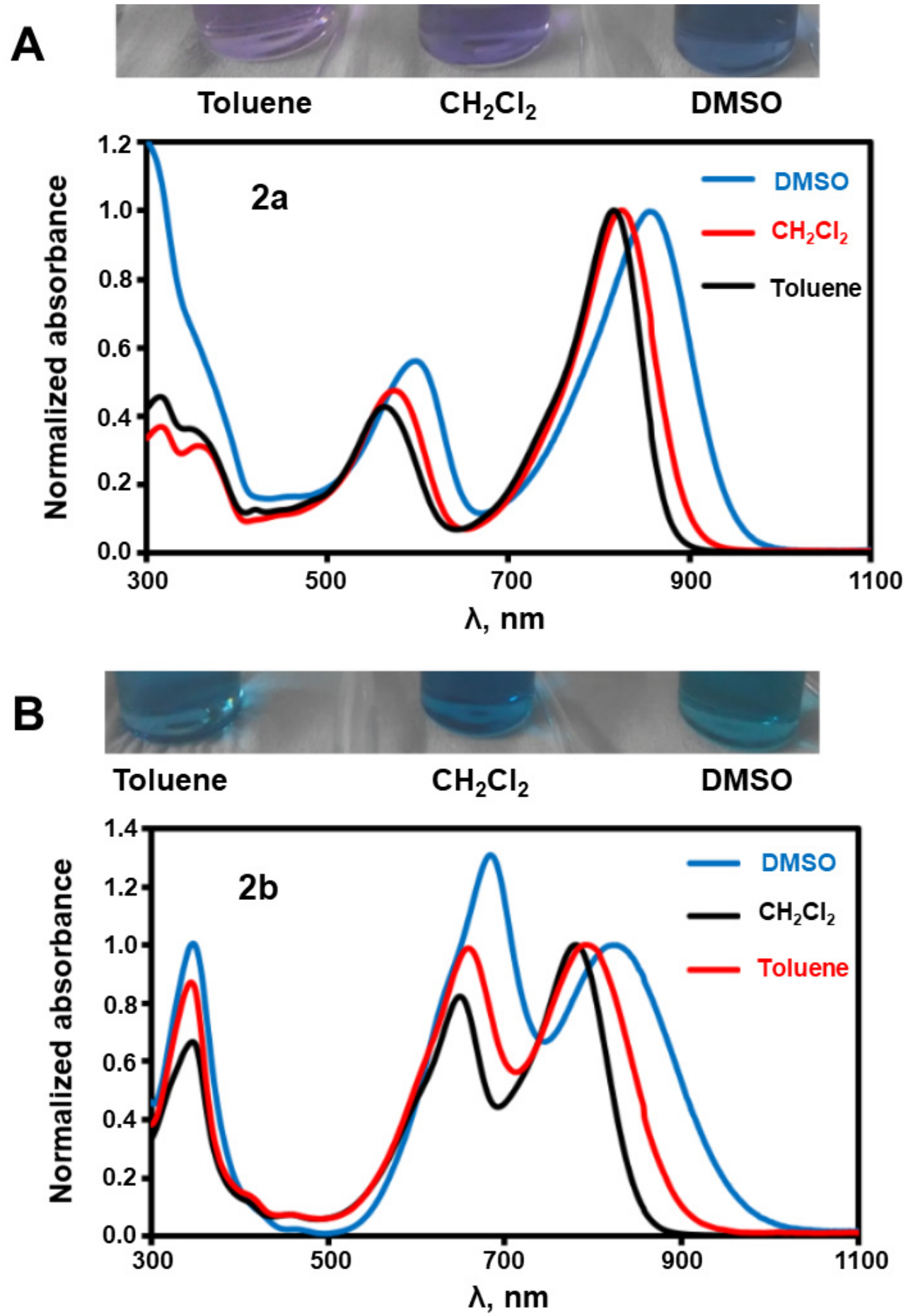

Figure 2. Solvatochromism effects on the optical properties of $\mathbf{2 a}$ and $\mathbf{2 b}$. Normalized UV-visible absorption spectra of (A) $2 \mathbf{a}$ and (B) $\mathbf{2 b}$ in dimethylsulfoxide (DMSO), $\mathrm{CH}_{2} \mathrm{Cl}_{2}$ and toluene.

\subsection{Effect of Protonation in $\mathrm{CH}_{2} \mathrm{Cl}_{2}$}

The effect of adding trifluoroacetic acid (TFA) to solutions of $\mathbf{2 a}$ and $\mathbf{2} \mathbf{b}$ in $\mathrm{CH}_{2} \mathrm{Cl}_{2}$ on the absorption and emission spectra was investigated. Protonation of $\mathbf{2} \mathbf{a}$ and $\mathbf{2} \mathbf{b}$ is accompanied by visible color 
changes, as shown in (Figure 3). O'Shea et al. have demonstrated that protonation disrupts the dimethylamino lone pair and this eliminates the ICT character of the $S_{1}$ state, and this results in a blue shift of the main spectral band and diminished absorbance [19]. In a similar manner, the addition of TFA to $\mathrm{CH}_{2} \mathrm{Cl}_{2}$ solutions of $\mathbf{2 a}$ and $\mathbf{2} \mathbf{b}$ results in a large blue shift of the main absorption bands (Figure 3). Upon addition of TFA to the $\mathrm{CH}_{2} \mathrm{Cl}_{2}$ solution of $\mathbf{2 a}$ solution, new bands are observed at 772 and $694 \mathrm{~nm}$ representing mono- and diprotonated species, respectively. The non-protonated species band at $824 \mathrm{~nm}$ gradually diminishes in intensity. The reasonably sharp isosbestic points at 790 and $746 \mathrm{~nm}$ provide an indication that points of equilibrium are reached during the addition of TFA (Figure 3). When TFA is added to the $\mathrm{CH}_{2} \mathrm{Cl}_{2}$ solution of $\mathbf{2 b}$, a new band appears at $731 \mathrm{~nm}$. The spectra of the mono- and diprotonated species are not as well defined in this case.
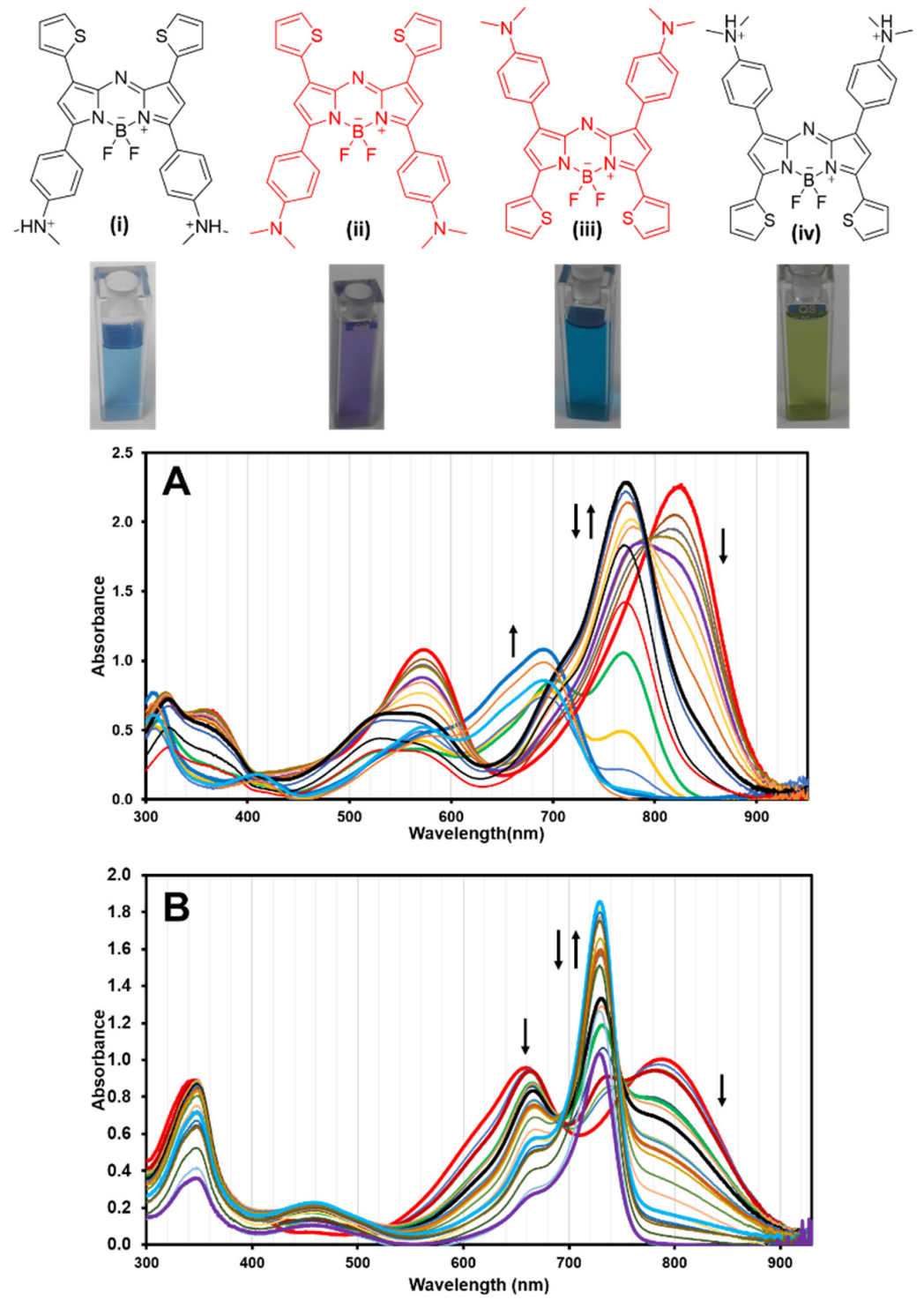

Figure 3. The diprotonated ((i) and (iv)) and non-protonated ((ii) and (iii)) structures of $\mathbf{2 a}$ and $\mathbf{2 b}$ and the observed colorimetric changes upon protonation with trifluoroacetic acid TFA (TOP). Effect of protonation (BOTTOM) on the absorption spectra of $\mathbf{2 a}(\mathbf{A})$ and $\mathbf{2 b}(\mathbf{b})$ in $\mathrm{CH}_{2} \mathrm{Cl}_{2}$.

The fluorescence spectra for $\mathrm{H}_{2} \mathbf{2} \mathbf{a}^{2+}$ and $\mathrm{H}_{2} \mathbf{2} \mathbf{b}^{2+}$ in $\mathrm{CH}_{2} \mathrm{Cl}_{2}$ are shown in Figure 4 . The fluorescence quantum yields $\left(\Phi_{\mathrm{F}}\right)$ were determined to be 0.04 and 0.14 in $\mathrm{CH}_{2} \mathrm{Cl}_{2}$, respectively. Relatively low $\Phi_{\mathrm{F}}$ values are expected for these compounds, since the values for NIR-emitting dyes are generally lower than for those emitting in the visible region [20]. The absence of fluorescence for $\mathbf{2} \mathbf{a}$ and $\mathbf{2} \mathbf{b}$ provides 
scope for a clear "turn-on" response for protonation in the NIR region. The response was found to be reversible when triethylamine (TEA) was added to reverse the $\mathrm{pH}$ change.
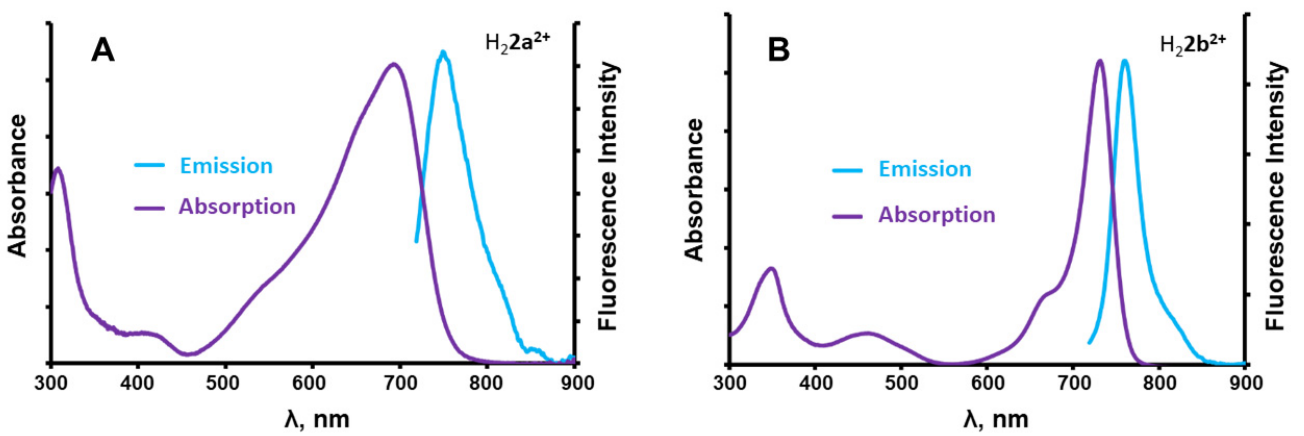

Figure 4. Absorption and emission spectra of $\mathrm{H}_{2} 2 \mathbf{a}^{2+}(\mathbf{A})$ and $\mathrm{H}_{2} \mathbf{2} \mathbf{b}^{2+}(\mathbf{B})$ in $\mathrm{CH}_{2} \mathrm{Cl}_{2}$ at $\lambda_{\mathrm{ex}}=600 \mathrm{~nm}$.

In addition to the UV-visible absorption and fluorescence titration data, ${ }^{1} \mathrm{H}$ NMR spectra were measured in $\mathrm{CDCl}_{3}$ to identify the site of protonation on $\mathbf{2 b}$ by using TFA as a titrant. $\mathbf{2 b}$ was sequentially titrated seven times with $50 \mu \mathrm{L}$ of concentrated TFA to increase the acidity of the solution, and a ${ }^{1} \mathrm{H}$ NMR spectrum was obtained at each step. Figure 5 provides a comparison of the ${ }^{1} \mathrm{H}$ NMR spectra of $\mathbf{2 b}$ in $\mathrm{CDCl}_{3}$ after the initial and final titrations. The initial titration results in a $0.14 \mathrm{M}$ TFA solution and drastically upfield shifted proton signals. It is evident that further titration ultimately resulted in no significant change in the aromatic and the dimethylamino proton signals, except for the deshielding effect induced by protonation. This demonstrates that $\mathbf{2} \mathbf{b}$ only undergoes protonation at the amino nitrogen atoms. The shift of the peak for the dimethylamino moieties from 3.08 to 3.37 ppm demonstrates that protonation occurs at the dimethylamino nitrogens. Initially upon forming the monocation species, rapid exchange of the proton between the two dimethylamino groups results in averaged NMR peaks. Subsequently, both groups are protonated when the dication is formed. The ${ }^{1} \mathrm{H}$ NMR spectra for the TFA titration of the dye (Figure S5, Supporting Information) reveal that an unusually broad signal due to TFA shifts across the aromatic region to ca. $8.5 \mathrm{ppm}$ with a simultaneous increase in intensity.

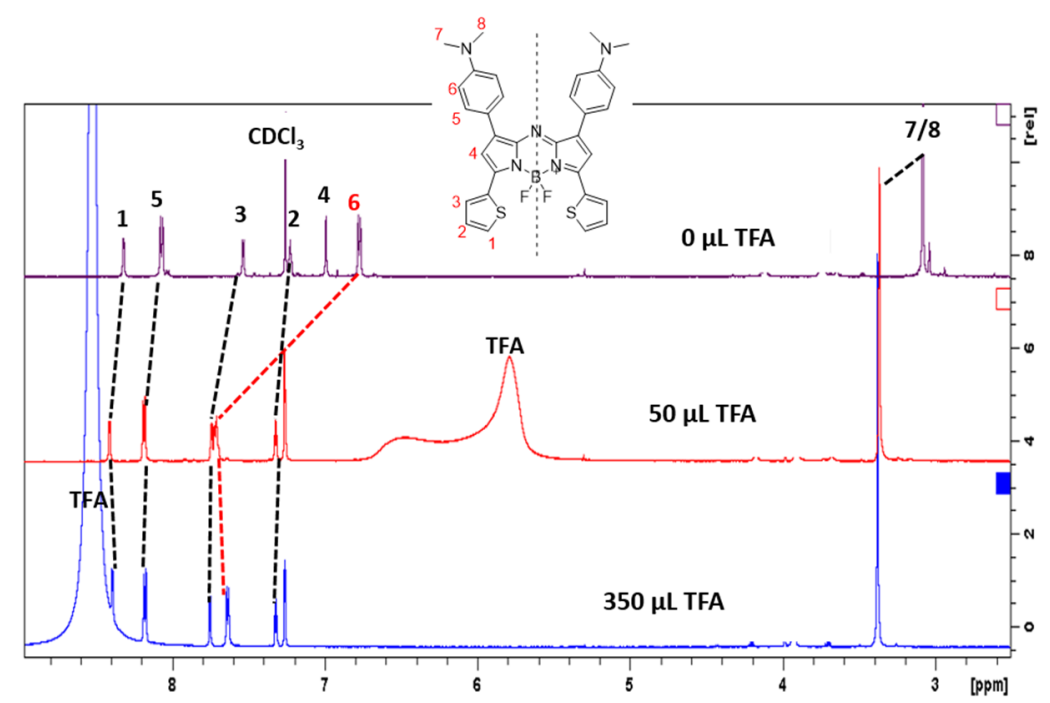

Figure 5. ${ }^{1} \mathrm{H}$ NMR spectroscopic titration of $\mathbf{2} \mathbf{b}$ with TFA in $\mathrm{CDCl}_{3}$. 


\section{Discussion}

\subsection{Effect of Protonation in DMSO/Aqueous Solutions}

Detailed protonation experiments were carried out in 2:1 (v/v) dimethyl sulfoxide (DMSO)/aqueous solutions, since both dyes are sufficiently soluble in this medium. In principle, the dyes should be suitable for use as acidic range $\mathrm{pH}$ indicators in the red/NIR spectral region due to the presence of the dimethylaminostyryl groups at the 1,7- and 3,5-positions. Aliquots of TFA in water were added, and spectral changes were monitored by UV-visible absorption and emission spectroscopy. The main azaBODIPY absorption band was found to undergo a significant red shift to $859 \mathrm{~nm}$ in 2:1 (v/v) DMSO/aqueous solution mixtures relative to what is observed in $\mathrm{CH}_{2} \mathrm{Cl}_{2}$ (Figure 3). The changes in absorption spectra in polar solvents upon protonation were similar to those reported above under TFA titration in $\mathrm{CH}_{2} \mathrm{Cl}_{2}$. There was a marked blue shift of the main absorption band to $778 \mathrm{~nm}$ for the monocation species and then to $682 \mathrm{~nm}$ for the dication species (Figure 6). Plots of absorbance against $\mathrm{pH}$ were used to identify isosbestic points, which are an indication of complete conversion between two distinct forms (Figure 6 insets). Reasonably sharp isosbestic points were observed for $2 \mathbf{a}$ at $\mathrm{pH}$ 1.71 (ca. $800 \mathrm{~nm}$ ) and at pH 1.14 and 0.23 (ca. $700 \mathrm{~nm}$ ), and for $\mathbf{2 b}$ at pH 1.34 (ca. $745 \mathrm{~nm}$ ) and pH 1.10 (ca. $700 \mathrm{~nm}$ ).
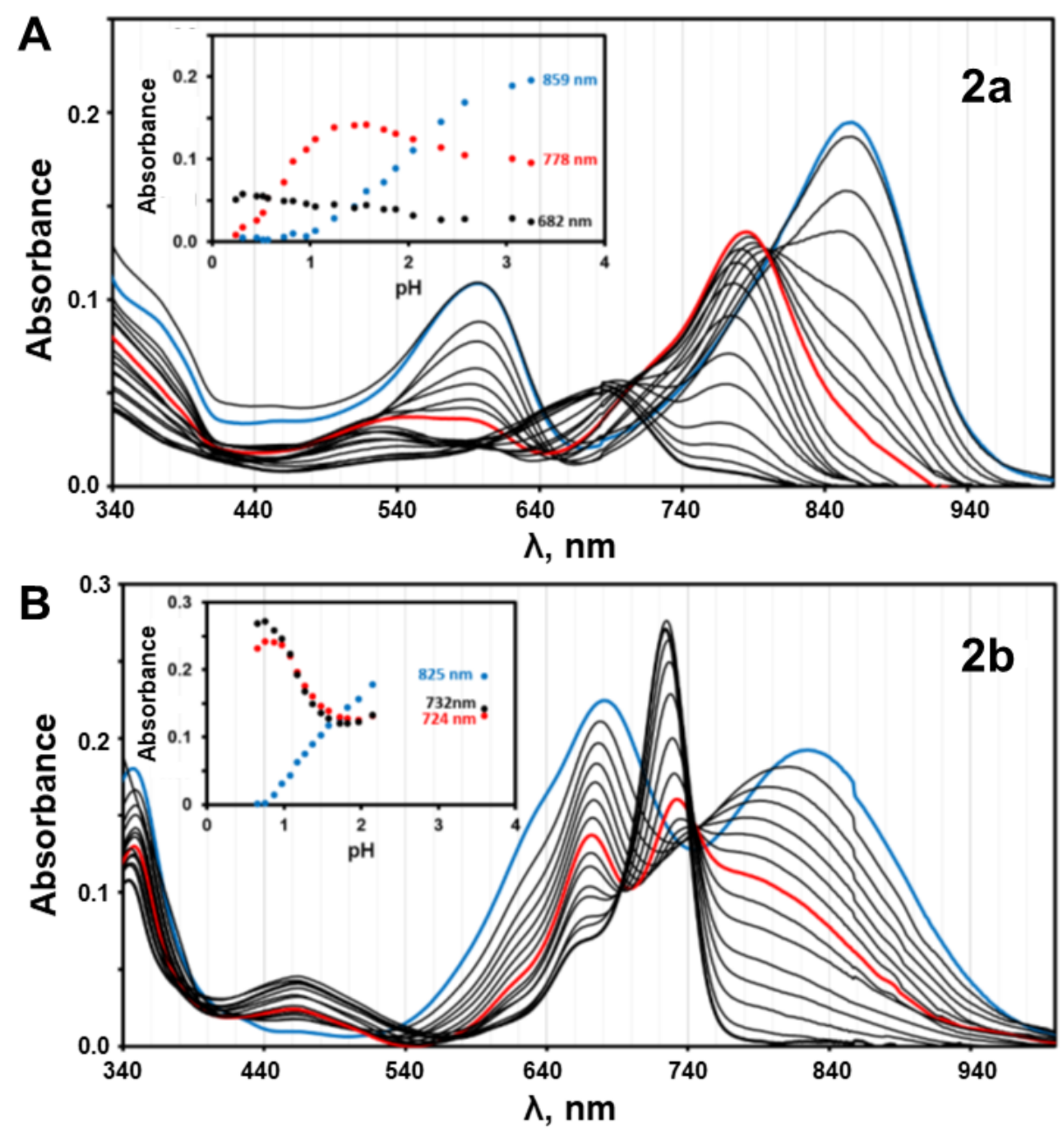

Figure 6. The $\mathrm{pH}$ dependence of absorbance for 2a in 2:1 (v/v) DMSO/aqueous solution (A) and the corresponding calibration curve (inset). The $\mathrm{pH}$ dependence of absorbance for $\mathbf{2} \mathbf{b}$ in $2: 1(v / v)$ DMSO/aqueous solution (B) and the corresponding calibration curve (inset). 
A significant increase was observed in the fluorescence intensity at 742 and $754 \mathbf{n m}$ for $\mathbf{2 a}$ and $\mathbf{2 b}$ when the acidity of the solutions was increased to very low $\mathrm{pH}$ values (Figure 7). Visible color changes are observed in this context (Figure 8), making the dyes potentially suitable for use as colorimetric indicators. These changes are consistent with ICT-restricted emission in the presence of dimethylamino groups, which is more pronounced for $2 \mathbf{a}$.
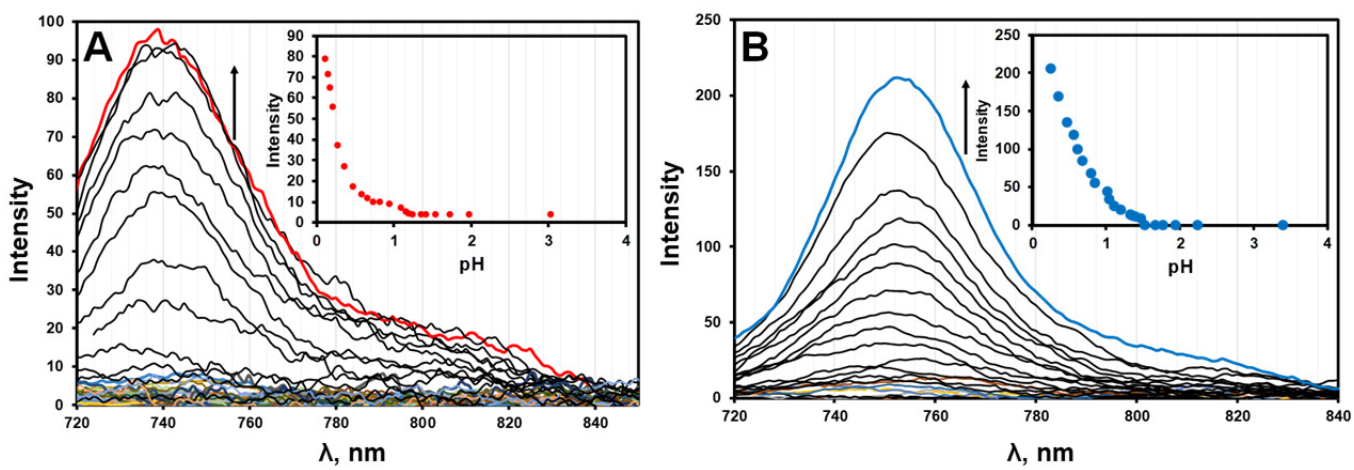

Figure 7. The $\mathrm{pH}$ dependence of emission for $(\mathbf{A}) \mathrm{H}_{2} \mathbf{2} \mathbf{a}^{2+}$ and $(\mathbf{B}) \mathrm{H}_{2} \mathbf{2} \mathbf{b}^{2+}$ in 2:1 (v/v) DMSO/aqueous solution $\left(1.41 \times 10^{-6} \mathrm{M}\right)$, and the corresponding $\mathrm{pH}$ calibration curves at the emission band maxima (insets).

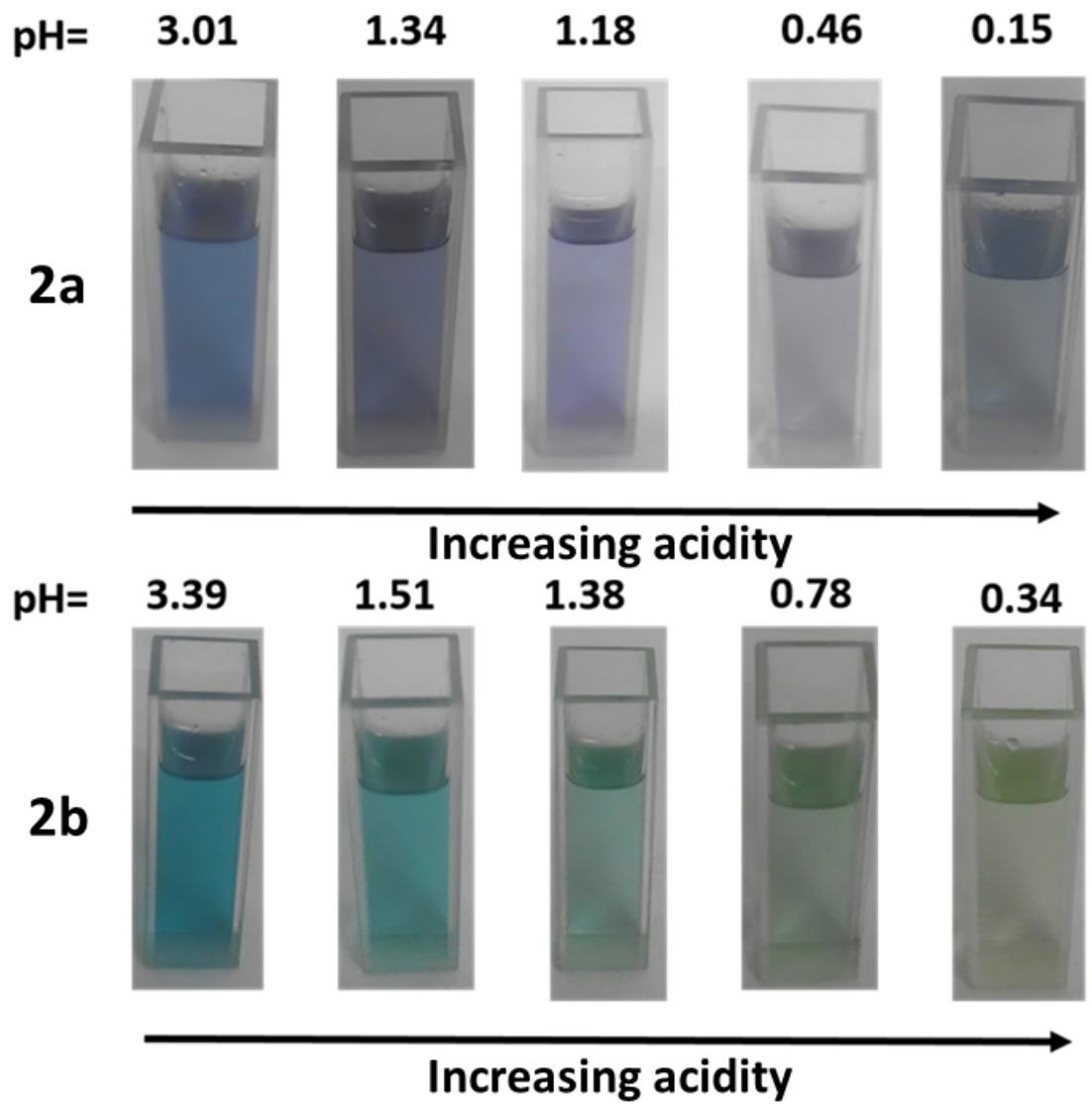

Figure 8. The colorimetric changes for $\mathbf{2 a}$ and $\mathbf{2 b}$ under different $\mathrm{pH}$ conditions in $2: 1(v / v)$ DMSO/aqueous solutions.

\section{2. $p K_{a}$ Determination}

The dissociation constant $\left(\mathrm{pK}_{\mathrm{a}}\right)$ values were determined to gain insight on their ionization states with respect to $\mathrm{pH}$. Both dyes were prepared in 2:1 (v/v) DMSO/aqueous buffered solutions (Table S1, 
Supporting Information), and the absorption measurements were made for the dye:buffer mixtures. Equation (1) was used to obtain approximate $\mathrm{pK}_{\mathrm{a}}$ values for $\mathbf{2 a}$ and $\mathbf{2 b}$ [21]:

$$
\mathrm{pK}_{\mathrm{a}}=\mathrm{pH}+\log \frac{\mathrm{d}_{\mathrm{M}}-\mathrm{d}}{\mathrm{d}-\mathrm{d}_{\mathrm{I}}}
$$

where $\mathrm{pH}$ is the value recorded on the $\mathrm{pH}$ meter and $\mathrm{d}$ is the absorbance of the molecule in the respective buffers tested. $d_{M}$ and $d_{I}$ are the absorbance of the non-protonated and protonated species, respectively. To verify the $\mathrm{pK}_{\mathrm{a}}$ results obtained, the inflection method reported was also used [22]. The inflection point is determined from a plot of absorbance against $\mathrm{pH}$, and a best-fit line is obtained by fitting the experimental data with a fourth-order polynomial (Figure 9). The results from both methods were found to be in close agreement. The spectroscopic behavior of both $\mathbf{2 a}$ and $\mathbf{2 b}$ reveals the presence of two $\mathrm{pK}_{\mathrm{a}}$ values. The $\mathrm{pK}_{\mathrm{a}}$ values of the non-protonated molecules are $6.9( \pm 0.05)$ and $7.3( \pm 0.05)$ for $\mathbf{2} \mathbf{a}$ and $\mathbf{2} \mathbf{b}$, respectively. The monoprotonated species for both dyes has a $\mathrm{pK}_{\mathrm{a}}$ value of $1.4( \pm 0.05)$, which is an increase of 0.1 compared to the apparent $\mathrm{pK}_{\mathrm{a}}$ value reported by McDonnell et al. [12] for the monoprotonated form of $\mathbf{1}$ [12]. The relative positions of the thien-2-yl and dimethylaniline groups was therefore found to have a negligible effect on the $\mathrm{pK}_{\mathrm{a}}$ value in this context.

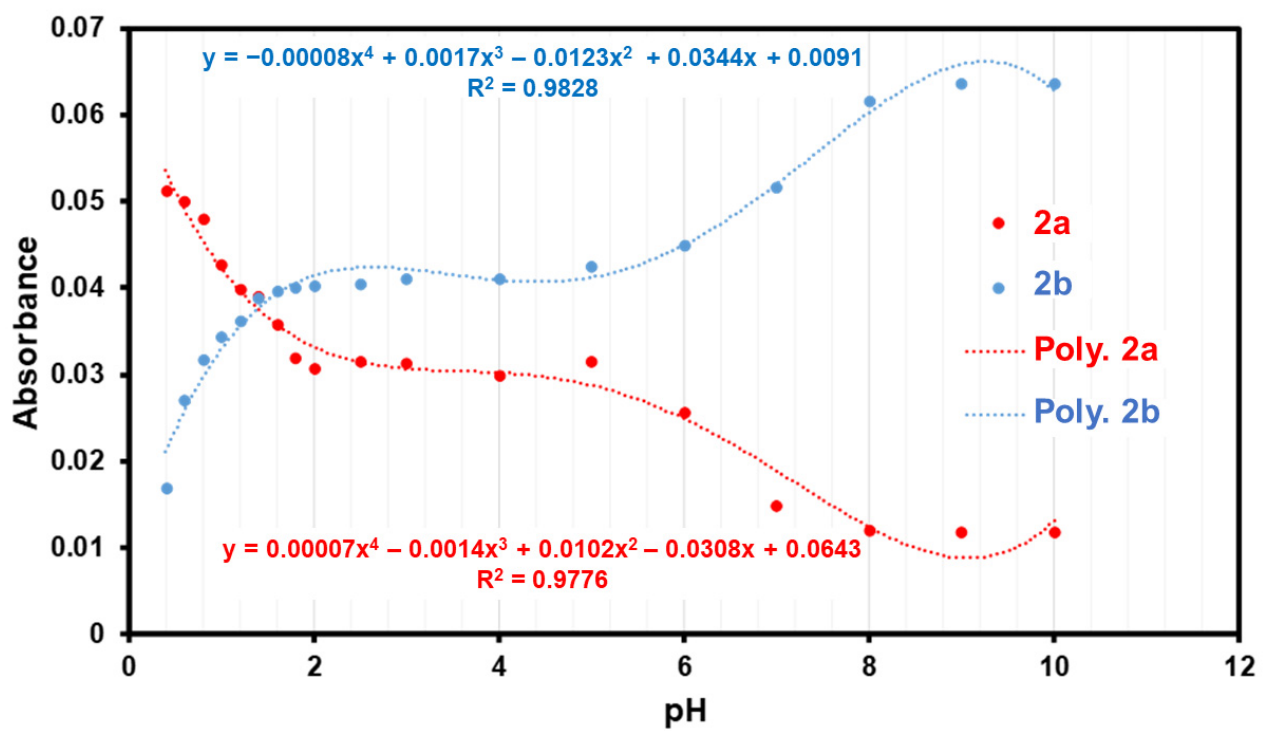

Figure 9. A plot of the observed absorbance values for $\mathbf{2 a}$ and $\mathbf{2 b}$ at 787 and $708 \mathrm{~nm}$, respectively, against $\mathrm{pH}$ trend for selected buffer solutions (Table S1, Supporting Information). The best-fit line is to a fourth-order polynomial, the equations are shown, along with the coefficient of determination $\left(\mathrm{R}^{2}\right)$.

\subsection{Molecular Modelling}

Theoretical calculations were carried out for the unsubstituted core dye (AzaBDY), 1,3,5,7-tetraphenyl (4Ph), 1,3,5,7-tetradimethylaniline (4An), and 1,3,5,7-tetrathien-2-yl (4Th) substituted azaBODIPY model complexes, $\mathbf{2} \mathbf{a}$ and $\mathbf{2} \mathbf{b}$ to obtain additional insight about the electronic structures and optical spectroscopy of $\mathbf{2} \mathbf{a}$ and $\mathbf{2} \mathbf{b}$ (Figure 10). The trends predicted in TD-DFT spectra of $\mathbf{2} \mathbf{a}$ and $\mathbf{2 b}$ match those observed experimentally (Table S2, Supporting Information). The incorporation of electron-rich dimethylaniline and thien-2-yl rings makes the azaBODIPY ligand results in a large destabilization of the HOMO energy [23,24]. As can be observed in Figure 10, the substitution of the thien-2-yl rings at the 1,3,5,7-positions of the 4Th model complex results in a slight stabilization of both the HOMO and LUMO relative to the $4 \mathrm{Ph}$ model complex, while the presence of electron-donating dimethylaniline rings in the 4An model complex results in a destabilization. In comparison to AzaBDY, the $4 \mathrm{Ph}, 4 \mathrm{An}$ and $4 \mathrm{Th}$ model complexes, and $\mathbf{2 a}$ and $\mathbf{2 b}$ are predicted to have significantly smaller HOMO-LUMO energy gaps (Figure 10). The differing arrangements of the substituents at the 
3,5- and 1,7-positions of the aza-BODIPY mainly influences the energy of the HOMO. The stronger electron-donating character of the dimethylaniline rings and the presence of large MO coefficients at the 3,5-positions (Figure 10) result in a larger destabilization of the HOMO of 2a than is the case with 2b. Protonation of the dimethylamine nitrogen shifts the electron density to the thien-2-yl groups in the HOMO (Figure 10), and this increases the HOMO-LUMO gap in a manner consistent with the observed blue shifts of the main spectral bands (Figures 3, 4 and 6).
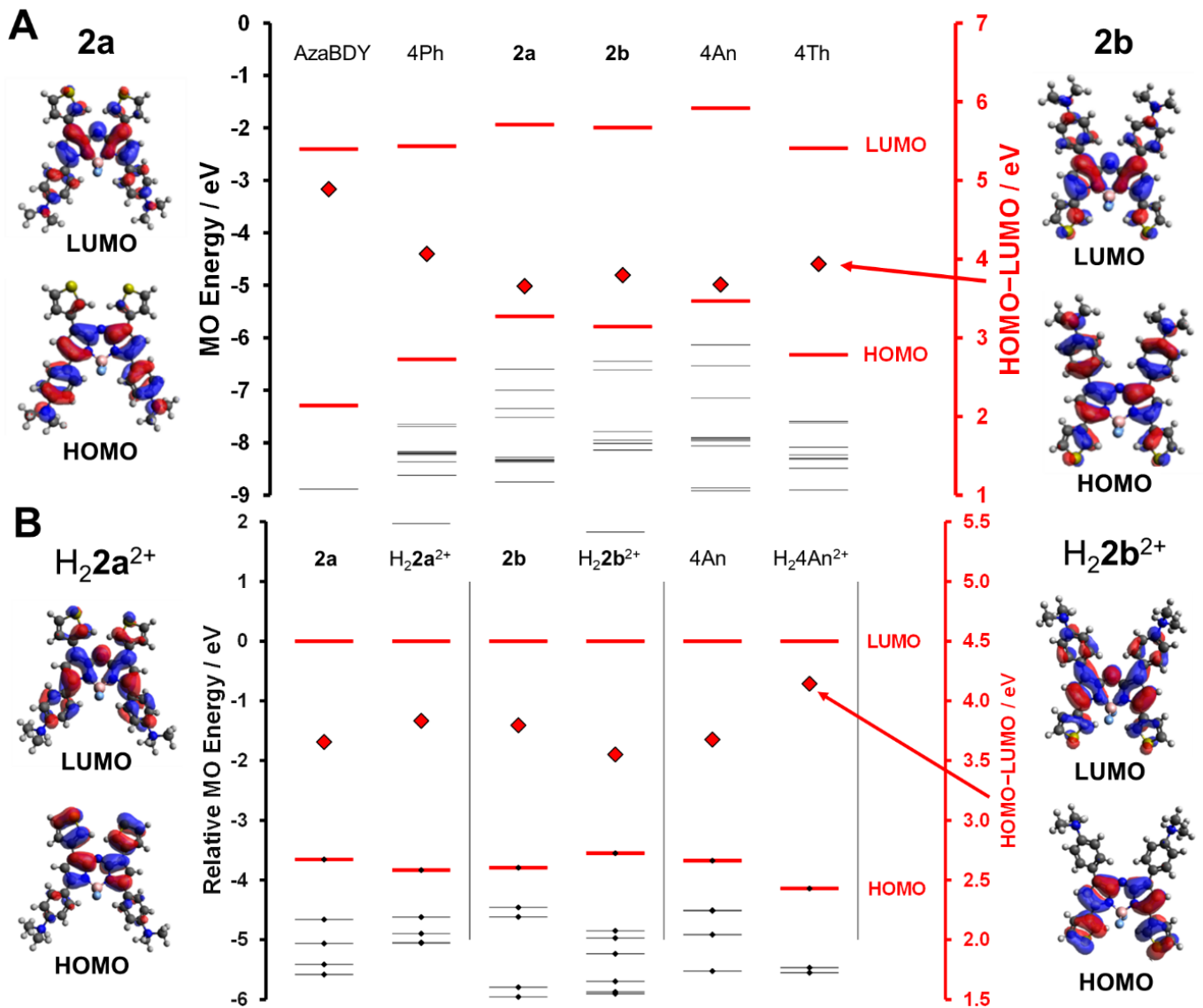

Figure 10. The HOMO and LUMO energies obtained from time-dependent density functional theory (TD-DFT) calculations at the CAM-B3LYP/5-31G(d) level of theory before (A) and after (B) protonation are highlighted with red lines. When a comparison is made with diprotonated species, the LUMO energy is set to zero. Small black squares are used to denote occupied MOs. Red diamonds are used to highlight the HOMO-LUMO band gap values and are plotted against a secondary axis. The angular nodal patterns of the HOMO and LUMO of the neutral (A) and diprotonated (B) species of $\mathbf{2 a}$ and $\mathbf{2 b}$ are shown at an isosurface of 0.02 a.u.

\section{Materials and Methods}

\subsection{Materials}

4-Dimethylaminoacetophenone, 4-dimethylaminobenzaldehyde, 2-acetylthiophene, thiophene-2carboxaldehyde, diethylamine (DEA), potassium hydroxide, nitromethane, potassium carbonate, $\mathrm{NH}_{4} \mathrm{OAc}, n$-BuOH were purchased from commercial suppliers in China. $\mathrm{BF}_{3} \cdot \mathrm{OEt}_{2}$, TFA, TEA, $\mathrm{NH}_{4} \mathrm{OAc}$, sodium sulfate anhydrous, sodium chloride, potassium hydrogen phthalate, potassium hydrogen phosphate, ethyl actetate, DMSO and DIPEA were purchased from Sigma Aldrich (St. Louis, MO, USA) and used as received. $\mathrm{CH}_{2} \mathrm{Cl}_{2}$, ethanol (EtOH), methanol, potassium chloride and hydrochloric acid were purchased from Minema (Johannesburg, South Africa). Sodium acetate was purchased from Saarchem (Johannesburg, South Africa), and acetic acid was purchased from B\&M Scientific 
(Cape Town, South Africa). All chemicals were analytically pure and were used as received. Acetone- $d_{6}$ and $\mathrm{CDCl}_{3}$ for ${ }^{1} \mathrm{H}$ NMR spectroscopy, and spectroscopic grade solvents for optical spectroscopy were purchased from Sigma-Aldrich and Merck (Darmstadt, Germany), respectively.

\subsection{Equipment}

${ }^{1} \mathrm{H}$ NMR spectra were recorded on a Bruker AMX 600 spectrometer (Billerica, MA, USA) at $600 \mathrm{MHz}$. Mass spectra were determined on a Bruker AutoFLEX III Smartbeam TOF MALDI-TOF mass spectrometer. The instrument was operated in positive ion mode with a $337 \mathrm{~nm}$ nitrogen laser and the data were obtained by using $\alpha$-cyano-4-hydroxycinnamic acid as the matrix. UV-visible absorption spectra were measured on a PerkinElmer Lambda 950 spectrophotometer (Waltham, MA, USA) operated over a wavelength range of 300-1200 nm. Fluorescence spectra were measured on a Varian Eclipse spectrofluorometer (Palo Alto, CA, USA). Fourier transform infrafred (FT-IR) spectra were recorded on an Alpha II (100 FT-IR) spectrometer (Bruker, Billerica, MA, USA) with a universal attenuated total reflectance (ATR) sampling accessory. All the data were obtained from neat particles. The $\mathrm{pH}$ values for the buffer solutions were measured using an 86555 Laboratory Benchtop digital $\mathrm{pH}$ meter (AZ Instrument Corp., Taichung City, China).

\subsection{Synthesis}

The first step in the preparation of $\mathbf{2 a}$ and $\mathbf{2} \mathbf{b}$ was the preparation of the appropriate chalcones $\mathbf{3}$ and nitro-derivatives 4 (Scheme 1). Potassium hydroxide $(0.16 \mathrm{~mol}$ ) dissolved in $5 \mathrm{~mL}$ water was added at room temperature to a $50 \mathrm{~mL}$ solution of the appropriate aryl ketone $(11.41 \mathrm{mmol})$ in ethanol. After stirring for $5 \mathrm{~min}$, an ethanol solution of the appropriate aryl aldehyde $(11.41 \mathrm{mmol})$, and the mixture was stirred for $24 \mathrm{~h}$. The precipitated products were filtered off, washed with aqueous ethanol, and dried. Recrystallization from methanol gave chalcones 3 as light-yellow solids in moderate yields [15]. 3 (100 mmol), nitromethane (500 mmol), and $\mathrm{K}_{2} \mathrm{CO}_{3}(0.2 \mathrm{mmol})$ were dissolved in ethanol $(50 \mathrm{~mL})$ and heated to reflux for $12 \mathrm{~h}$. After cooling to rt, the solvent was removed in vacuum and the oily residue obtained was dissolved in ethyl acetate and washed with water three times. The combined organic layers were washed with brine, dried over sodium sulfate, and concentrated to give 4 as yellowish oily residues in nearly quantitative yields, which were used in the next step without further purification [16].

Azadipyrromethenes 5 were used to prepare $\mathbf{2 a}$ and $\mathbf{2 b}$ (Scheme 1). A mixture of $\mathbf{4}(1 \mathrm{mmol})$ and $\mathrm{NH}_{4} \mathrm{OAc}(20 \mathrm{mmol})$ was refluxed in $n-\mathrm{BuOH}(50 \mathrm{~mL})$ for $24 \mathrm{~h}$. After cooling to rt, the reaction mixture was diluted with water and extracted three times with $\mathrm{CH}_{2} \mathrm{Cl}_{2}$. The combined organic layers were washed with water and brine, dried with sodium sulfate, and concentrated to give the crude intermediate product 5 as a dark blue-black solid, which was then purified by column chromatography prior to use to form the target compounds. DIPEA $(0.8 \mathrm{~mL}, 4.8 \mathrm{mmol})$ was added to a solution of $5(1 \mathrm{mmol})$ in $\mathrm{CH}_{2} \mathrm{Cl}_{2}(50 \mathrm{~mL})$, and the mixture was stirred for $1 \mathrm{~h} . \mathrm{BF}_{3} \cdot \mathrm{OEt}_{2}(0.6 \mathrm{~mL}, 5.0 \mathrm{mmol})$ was then added at $\mathrm{rt}$, and the resulting mixture refluxed until the starting material was completely converted (ca. $2 \mathrm{~h}$ ) to the target product. The progress of the reaction was monitored by thin-layer chromatography (TLC). The cold reaction mixture was diluted with water and extracted twice with $\mathrm{CH}_{2} \mathrm{Cl}_{2}(100 \mathrm{~mL})$. The combined organic layers were dried with sodium sulfate and concentrated under vacuum. The crude products were purified by flash column chromatography using $\mathrm{CH}_{2} \mathrm{Cl}_{2} /$ hexane (2:1) as eluent. Target compounds $\mathbf{2} \mathbf{a}$ and $\mathbf{2} \mathbf{b}$ were obtained as shiny coppery crystals:

2a was obtained in $62 \%$ yield; UV-vis (DMSO) $\lambda / \mathrm{nm}(\log \varepsilon) 859$ (4.8); IR (FT-IR) $v_{\max } / \mathrm{cm}^{-1}: 2952$ (=C-H stretch, 858 (-C-H stretch), 1666 (C=N stretch), 1598-1543 (Ar C-C), 1368-1030 (C-N stretch); ${ }^{1} \mathrm{H}$ NMR $\left(600 \mathrm{MHz}\right.$, Acetone- $\left.d_{6}\right)$ : $\delta / \mathrm{ppm} 3.15\left(12 \mathrm{H}, \mathrm{s}, \mathrm{NCH}_{3}\right), 6.86(4 \mathrm{H}, \mathrm{d}, J=9.6 \mathrm{~Hz}, \mathrm{Ar}-\mathrm{H}), 7.24(2 \mathrm{H}$, $\mathrm{dd}, J=0.9$ and $5.1 \mathrm{~Hz}, \mathrm{Ar}-\mathrm{H}), 7.37(2 \mathrm{H}, \mathrm{s}, \mathrm{Ar}-\mathrm{H}), 7.69(2 \mathrm{H}, \mathrm{dd}, J=0.9$ and $5.1 \mathrm{~Hz}, \mathrm{Ar}-\mathrm{H}), 8.06(2 \mathrm{H}, \mathrm{dd}$, $J=1.2$ and $3.6 \mathrm{~Hz}, \mathrm{Ar}-\mathrm{H}), 8.22(4 \mathrm{H}, \mathrm{d}, J=9.6 \mathrm{~Hz}, \mathrm{Ar}-\mathrm{H})$; MS (MALDI-TOF): Anal. calc. $m / z$ 595.19; Found: [M] ${ }^{+}$594.96; Anal. calc. for $\left[\mathrm{C}_{32} \mathrm{H}_{28} \mathrm{BF}_{2} \mathrm{~N}_{5} \mathrm{~S}_{2}\right]$ : C, 64.54; $\mathrm{H}, 4.74 ; \mathrm{N}, 11.76 ; \mathrm{S}, 10.77$; Found: $\mathrm{C}$, 64.30; $\mathrm{H}, 4.68 ; \mathrm{N}, 11.80, \mathrm{~S}, 10.80$. 
2b was obtained in $74 \%$ yield; UV-vis (THF) $\lambda / \mathrm{nm}$ (log $\varepsilon$ ) 786 (4.7); IR (FT-IR) $v_{\max } / \mathrm{cm}^{-1}: 2952$ (=C-H stretch), 2857 (-C-H stretch), 1667 (C=N stretch), 1598-1543 (Ar C-C), 1368-1030 (C-N stretch); ${ }^{1} \mathrm{H}$ NMR $\left(600 \mathrm{MHz}, \mathrm{CDCl}_{3}\right): \delta / p p m 3.09\left(12 \mathrm{H}, \mathrm{s}, \mathrm{NCH}_{3}\right), 6.77(4 \mathrm{H}, \mathrm{d}, J=9.0 \mathrm{~Hz}, \mathrm{Ar}-\mathrm{H}), 6.99(2 \mathrm{H}, \mathrm{s}$, Ar-H), $7.23(2 \mathrm{H}, \mathrm{dd}, J=3.6$ and $4.8 \mathrm{~Hz}, \mathrm{Ar}-\mathrm{H}), 7.54(2 \mathrm{H}, \mathrm{d}, J=4.2 \mathrm{~Hz}, \mathrm{Ar}-\mathrm{H}), 8.07(4 \mathrm{H}, \mathrm{d}, J=9.0 \mathrm{~Hz}$, Ar-H), 8.32 (2H, d, $J=3.6 \mathrm{~Hz}, \mathrm{Ar}-\mathrm{H})$; MS (MALDI-TOF): Anal. calc. $m / z$ 595.19; Found: $[\mathrm{M}]^{+}$595.00; Anal. calc. for $\left[\mathrm{C}_{32} \mathrm{H}_{28} \mathrm{BF}_{2} \mathrm{~N}_{5} \mathrm{~S}_{2}\right]: \mathrm{C}, 64.54 ; \mathrm{H}, 4.74 ; \mathrm{N}, 11.76 ; \mathrm{S}, 10.77$; Found: $\mathrm{C}, 64.50 ; \mathrm{H}, 4.60 ; \mathrm{N}, 11.68$, S, 10.82 .

\subsection{Photophysical Parameters}

A comparative method was used to determine fluorescence quantum yield $\left(\Phi_{\mathrm{F}}\right)$ values:

$$
\Phi_{\mathrm{F}}=\Phi_{\mathrm{F}(\mathrm{std})} \times \frac{\mathrm{F} \mathrm{A}_{\mathrm{std}} \eta^{2}}{\mathrm{~F}_{\text {std }} \mathrm{A} \eta^{2} \text { std }}
$$

where $F$ and $F_{\text {std }}$ are the areas under the fluorescence curves of $\mathbf{2 a}$ and $\mathbf{2 b}$ and the reference, respectively. $A$ and $A_{\text {std }}$ are the absorbances of sample and reference at the excitation wavelength, and $\eta^{2}$ and $\eta^{2}$ std are the refractive indices of solvents used for the sample and the reference measurements, respectively. IR-820 was used as the standard; $\Phi_{\mathrm{F}}=0.044$ in methanol [25].

\section{5. pH Studies}

The effect of protonation on $\mathbf{2 a}$ and $\mathbf{2 b}$ was investigated through the addition of aliquots of $\mathbf{a}$ dilute TFA solution in $\mathrm{CH}_{2} \mathrm{Cl}_{2}$. $3000 \mu \mathrm{L}$ of TFA in $7000 \mu \mathrm{L}(6000 \mu \mathrm{L}$ in the case of $\mathbf{2 b})$ of Millipore water was prepared and used for the $\mathrm{pH}$ studies. Concentrations of $3.2 \times 10^{-6}$ and $3.6 \times 10^{-5} \mathrm{M}$ of $\mathbf{2 a}$ and $\mathbf{2 b}$, respectively, were used in $4 \mathrm{~mL}$ of solution. A total of $50 \mu \mathrm{L}$ of the TFA solution was added gradually, and changes in $\mathrm{pH}$ were monitored. The buffer solutions were prepared according to literature procedures [26] with slight modifications (Table S1, Supporting Information). A UV-visible absorption spectroscopy method was used to determine the $\mathrm{pK}_{\mathrm{a}}$ value. Stock solutions of $1.5 \times 10^{-6}$ and $1.9 \times 10^{-5} \mathrm{M}$ of $\mathbf{2 a}$ and $\mathbf{2 b}$, respectively, were prepared in DMSO. The vials were filled with different buffers of constant ionic strength $(I=1 \mathrm{M})$, ranging from $\mathrm{pH}$ 0.4 to 9.0. A fixed amount of stock solution for both compounds was added to each vial and mixed, except in vials that were used as blank buffers to provide correction factors.

\subsection{Theoretical Calculations}

The Gaussian 09 software package [27] was used to carry out density functional theory (DFT) geometry optimizations at the B3LYP/6-31G(d) level of theory for $\mathbf{2 a}, \mathbf{2} \mathbf{b}$ and a series of model complexes. Time dependent-DFT (TD-DFT) calculations were carried out by using the CAM-B3LYP functional with 6-31G(d) basis sets. The CAM-B3LYP functional was used since it contains a long-range correction that makes it more suitable for use with dyes that exhibit ICT character.

\section{Conclusions}

Two pH-sensitive NIR absorbing azaBODIPY dyes have been successfully synthesized and characterized. The introduction of electron-donating dimethylaniline and thien-2-yl groups results in unusually large red shifts of the main azaBODIPY absorption band well into the NIR region at 824 and $790 \mathrm{~nm}$, respectively, in $\mathrm{CH}_{2} \mathrm{Cl}_{2}$. A larger red shift is observed for $2 \mathbf{a}$, since the more strongly electron-donating dimethylaniline rings lie at the 3,5-positions, which have large MO coefficients in the HOMO. A relative destabilization of the HOMO results in a narrowing of the HOMO-LUMO gap. In bulk solution, the dyes are only fluorescent under acidic conditions, due to suppression of the ICT process upon protonation. This provides scope for a $\mathrm{pH}$-dependent fluorescence "turn-on" effect. 2a with strongly electron-donating dimethylaniline rings at the 3,5-positions has a $\mathrm{pK}_{\mathrm{a}}$ value of $6.9( \pm 0.05)$ and is more strongly acidic than $2 \mathbf{b}$, which has a $\mathrm{pK}_{\mathrm{a}}$ value of $7.3( \pm 0.05)$. The monoprotonated 
species of $\mathbf{2 a}$ and $\mathbf{2} \mathbf{b}$ were estimated to have $\mathrm{pK}_{\mathrm{a}}$ values of $1.4( \pm 0.05)$. The visible colorimetric changes under acidic conditions demonstrate that $\mathbf{2} \mathbf{a}$ and $\mathbf{2} \mathbf{b}$ are good candidates for use as $\mathrm{pH}$ indicators under strongly acidic conditions.

Supplementary Materials: The following are available online. Figure S1: 1H NMR spectrum of 2a in acetone-d6, Figure S2: $1 \mathrm{H}$ NMR spectrum of $2 \mathrm{~b}$ in $\mathrm{CDCl}_{3}$, Figure S3: MS data for 2a, Figure S4: MS data for 2b, Figure S5: Stacked $1 \mathrm{H}$ NMR spectra for $2 \mathrm{~b}$ titrated with TFA in $\mathrm{CDCl}_{3}$, Table S1: Preparation of buffer solutions of constant ionic strength $(I=1 \mathrm{M})$, Table S2: Calculated electronic excitation spectra of $\mathbf{2} \mathbf{a}$ and $\mathbf{2} \mathbf{b}$ at the CAM-B3LYP/6-31G(d) level of theory.

Author Contributions: Conceptualization, G.K., J.M. and Z.S.; methodology, G.K., J.M. and Z.S.; validation, G.K., J.M. and Z.S.; formal analysis, G.K.; investigation, G.K.; resources, J.M., T.N. and Z.S.; data curation, G.K., J.M. and Z.S.; writing —original draft preparation, G.K.; writing—review and editing, G.K., J.M., T.N. and Z.S.; supervision, J.M. and T.N.; project administration, J.M., T.N. and Z.S.; funding acquisition, J.M., T.N. and Z.S. All authors have read and agreed to the published version of the manuscript.

Funding: This research was funded by a China-South Africa joint research program (CS08-L07 and uid: 95421) to Z.S. and J.M., Competitive Support for Unrated Researchers and Incentive Support for Rated Researchers grants from the National Research Foundation of South Africa (uids: 93627 \& 119259) to J.M., by the National Natural Science Foundation of China (No. 21771102) to Z.S., the Department of Science and Technology (DST) and NRF of South Africa through a DST/NRF South African Research Chairs Initiative for Professor of Medicinal Chemistry and Nanotechnology (uid: 62620) to T.N., and an NRF-DAAD bursary to G.K.

Acknowledgments: Photophysical measurements were made possible by the Laser Rental Pool Programme of the Council for Scientific and Industrial Research (CSIR) of South Africa. The theoretical calculations were carried out at the Centre for High-Performance Computing in Cape Town.

Conflicts of Interest: The authors declare no conflict of interest.

\section{References}

1. Ni, Y.; Wu, J. Far-red and near infrared BODIPY dyes: Synthesis and applications for fluorescent pH probes and bio-imaging. Org. Biomol. Chem. 2014, 12, 3774-3791. [CrossRef] [PubMed]

2. Kiyose, K.; Kojima, H.; Urano, Y.; Nagano, T. Development of a Ratiometric Fluorescent Zinc Ion Probe in Near-Infrared Region, Based on Tricarbocyanine Chromophore. J. Am. Chem. Soc. 2006, 128, 6548-6549. [CrossRef] [PubMed]

3. Loudet, A.; Bandichhor, R.; Burgess, K.; Palma, A.; McDonnell, S.O.; Hall, M.; O'Shea, D.F. B,O-Chelated Azadipyrromethenes as Near-IR Probes. Org. Lett. 2008, 10, 4771-4774. [CrossRef] [PubMed]

4. Gut, A.; Łapok, Ł.; Drelinkiewicz, D.; Pedzinski, T.; Marciniak, B.; Nowakowska, M. Visible-Light Photoactive, Highly Efficient Triplet Sensitizers Based on Iodinated Aza-BODIPYs: Synthesis, Photophysics and Redox Properties. Chem. Asian J. 2017, 13, 55-65. [CrossRef] [PubMed]

5. Gresser, R.; Hartmann, H.; Wrackmeyer, M.; Leo, K.; Riede, M.K. Synthesis of thiophene-substituted aza-BODIPYs and their optical and electrochemical properties. Tetrahedron 2011, 67, 7148-7155. [CrossRef]

6. Wu, Y.; Cheng, C.; Jiao, L.; Yu, C.; Wang, S.; Wei, Y.; Mu, X.; Hao, E. $\beta$-Thiophene-Fused BF2-Azadipyrromethenes as Near-Infrared Dyes. Org. Lett. 2014, 16, 748-751. [CrossRef]

7. Zhang, X.; Yu, H.; Xiao, Y. Replacing Phenyl Ring with Thiophene: An Approach to Longer Wavelength Aza-dipyrromethene Boron Difluoride (Aza-BODIPY) Dyes. J. Org. Chem. 2011, 77, 669-673. [CrossRef]

8. Jiang, X.-D.; Zhao, J.; Li, Q.; Sun, C.-L.; Guan, J.; Sun, G.-T.; Xiao, L.-J. Synthesis of NIR fluorescent thienyl-containing aza-BODIPY and its application for detection of $\mathrm{Hg}^{2+}$ : Electron transfer by bonding with $\mathrm{Hg}^{2+}$. Dyes and Pigments 2016, 125, 136-141. [CrossRef]

9. Zhao, W.; Carreira, E. Conformationally Restricted Aza-Bodipy: A Highly Fluorescent, Stable, Near-Infrared-Absorbing Dye. Angew. Chem. Int. Ed. 2005, 44, 1677-1679. [CrossRef]

10. Killoran, J.; Allen, L.; Gallagher, J.F.; Gallagher, W.M.; O'Shea, D.F. Synthesis of BF 2 chelates of tetraarylazadipyrromethenes and evidence for their photodynamic therapeutic behaviour. Chem. Commun. 2002, 1862-1863. [CrossRef]

11. Andersson, P.; Gillbro, T.; Asato, A.; Liu, R. Dual singlet state emission in a series of mini-carotenes. J. Lumin. 1992, 51, 11-20. [CrossRef]

12. McDonnell, S.O.; O'Shea, D.F. Near-infrared sensing properties of dimethlyamino-substituted $\mathrm{BF}_{2}$-azadipyrromethenes. Org. Lett. 2006, 8, 3493-3496. [CrossRef] [PubMed] 
13. Maus, M.; Rurack, K. Monitoring $\mathrm{pH}$ and solvent proticity with donor-acceptor-substituted biphenyls: A new approach towards highly sensitive and powerful fluorescent probes by tuning the molecular structure. New J. Chem. 2000, 24, 677-686. [CrossRef]

14. Li, C.-Y.; Zhang, X.-B.; Qiao, L.; Zhao, Y.; He, C.-M.; Huan, S.; Lu, L.-M.; Jian, L.-X.; Shen, G.-L.; Yu, R.-Q. Naphthalimide-Porphyrin Hybrid Based Ratiometric Bioimaging Probe for Hg2+: Well-Resolved Emission Spectra and Unique Specificity. Anal. Chem. 2009, 81, 9993-10001. [CrossRef] [PubMed]

15. Dannhardt, G.; Kiefer, W.; Krämer, G.; Maehrlein, S.; Nowe, U.; Fiebich, B. The pyrrole moiety as a template for COX-1/COX-2 inhibitors. Eur. J. Med. Chem. 2000, 35, 499-510. [CrossRef]

16. Peseke, K.; Gotze, L.; Reinke, H.; Cedeño, Q.A.; Suárez, J.Q.; Andreu, M.G.; Castro, H.V. A Synthesis of Substituted Tetrahydro-2-pyranols. J. Prakt. Chem. 1997, 339, 656-659. [CrossRef]

17. Lu, H.; Mack, J.; Yang, Y.; Shen, Z. Structural modification strategies for the rational design of red/NIR region BODIPYs. Chem. Soc. Rev. 2014, 43, 4778-4823. [CrossRef]

18. Yang, W.; Liu, H.-G.; Liu, G.-K.; Lin, Y.; Gao, M.; Zhao, X.-Y.; Zheng, W.-C.; Chen, Y.; Xu, J.; Li, L.-Z. Trivalent europium-doped strontium molybdate red phosphors in white light-emitting diodes: Synthesis, photophysical properties and theoretical calculations. Acta Mater. 2012, 60, 5399-5407. [CrossRef]

19. Gorman, A.; Killoran, J.; O'Shea, C.; Kenna, T.; Gallagher, W.M.; O'Shea, D.F. In Vitro Demonstration of the Heavy-Atom Effect for Photodynamic Therapy. J. Am. Chem. Soc. 2004, 126, 10619-10631. [CrossRef]

20. Jokić, T.; Borisov, S.M.; Saf, R.; Nielsen, D.A.; Kühl, M.; Klimant, I. Highly Photostable Near-Infrared Fluorescent $\mathrm{pH}$ Indicators and Sensors Based on $\mathrm{BF}_{2}-$ Chelated Tetraarylazadipyrromethene Dyes. Anal. Chem. 2012, 84, 6723-6730. [CrossRef]

21. Pandey, M.; Jaipal, A.; Kumar, A.; Malik, R.; Charde, S. Determination of $\mathrm{pK}_{\mathrm{a}}$ of felodipine using UV-Visible spectroscopy. Spectrochim. Acta 2013, 115, 887-890. [CrossRef] [PubMed]

22. Horton, H.R.; Moran, L.A.; Ochs, R.S.; Rawn, J.D.; Scrimgeour, K.G. Principles of Biochemistry; Prentice Hall: Bergen County, NJ, USA, 1996.

23. Raposo, M.M.M.; Fonseca, A.; Castro, M.C.R.; Belsley, M.; Cardoso, M.; Carvalho, L.; Coelho, P. Synthesis and characterization of novel diazenes bearing pyrrole, thiophene and thiazole heterocycles as efficient photochromic and nonlinear optical (NLO) materials. Dye. Pigment. 2011, 91, 62-73. [CrossRef]

24. Tejada, R.P.; Pellejà, L.; Palomares, E.; Franco, S.; Orduna, J.; Garín, J.; Andreu, R. Novel 4 H -pyranylidene organic dyes for dye-sensitized solar cells: Effect of different heteroaromatic rings on the photovoltaic properties. Org. Electron. 2014, 15, 3237-3250. [CrossRef]

25. James, N.S.; Chen, Y.; Joshi, P.; Ohulchanskyy, T.Y.; Ethirajan, M.; Henary, M.; Strekowsk, L.; Pandey, R.K. Evaluation of Polymethine Dyes as Potential Probes for Near Infrared Fluorescence Imaging of Tumors: Part-1. Theranostics 2013, 3, 692-702. [CrossRef]

26. Martínez, C.H.R.; Dardonville, C. Rapid Determination of Ionization Constants $\left(\mathrm{pK}_{\mathrm{a}}\right)$ by UV Spectroscopy Using 96-Well Microtiter Plates. ACS Med. Chem. Lett. 2012, 4, 142-145. [CrossRef]

27. Gaussian 09, Revision D. 01; Gaussian Inc.: Wallingford, CT, USA, 2009.

Sample Availability: Samples of compounds $\mathbf{2 a}$ and $\mathbf{2 b}$ are available from the authors.

(C) 2020 by the authors. Licensee MDPI, Basel, Switzerland. This article is an open access article distributed under the terms and conditions of the Creative Commons Attribution (CC BY) license (http://creativecommons.org/licenses/by/4.0/). 